\title{
Biliary bile acids in cholelithiasis and colon cancer
}

\author{
W M CAStleden, P DETCHON, AND $N$ L A Misso
}

From the Department of Surgery, The University of Western Australia, Queen Elizabeth II Medical Centre, Nedlands, Western Australia

SUMmaRy The role of biliary deoxycholate as an endogenous colon carcinogen and the possible association between cholelithiasis and/or cholecystectomy and the subsequent development of large bowel cancer is unclear. This paper describes biliary bile acids analysis performed on 13 patients undergoing cholecystectomy for gall stones, 10 patients undergoing colonic resection for colon cancer, and eight control patients. For all 31 patients the total bile acids concentration was highly variable $(8 \cdot 3 \mathrm{mg} / \mathrm{ml}-106 \cdot 5 \mathrm{mg} / \mathrm{ml})$. The median ratio of primary to secondary bile acids was $2 \cdot 7: 1$. The biliary bile acid ratios were similar in both control patients $(3 \cdot 7: 1)$ and those with colon cancer $(3 \cdot 1: 1)$, whereas patients with gall stones had significantly higher secondary bile acid levels in their biliary bile (ratio 1.9:1, $p=<0 \cdot 05$ ). This result indicates that raised biliary deoxycholate concentrations are not present in patients with colon cancer and are therefore unlikely to be a major predisposing factor in the aetiology of this disease. It is unlikely that cholelithiasis and/or cholecystectomy predispose to the subsequent development of colon tumours.

Many studies have reported a positive association between the incidence of cholelithiasis or cholecystectomy and colon cancer. ${ }^{1-16}$ In some reports the significant association was reported to be sex-specific (women) and/or site-specific (right sided colon tumours) and/or geographically specific (Western diet countries). As a result, the theory that either cholelithiasis or cholecystectomy does indeed predispose to colon cancer has become almost an accepted dogma. This theory has evolved from the studies of Hill and coworkers ${ }^{17-210}$ who showed a higher incidence of colon cancer in populations containing relatively more strains of gut anaerobes able to degrade the primary bile acid cholic acid to the secondary bile acid deoxycholic acid, and the close resemblance between dexycholic acid and known carcinogens such as methylcholanthrene. Hill $^{21}$ has proposed that excessive exposure of the colonic mucosa to degraded bile salts, especially deoxycholate (such as occurs in gall bladder disease $^{22.3}$ ) is a causative factor in the development of colon cancer. Because the type of bacterial flora

Address for correspondence: Mr W M Castleden, FRACS, Dept of Surgery. Fremantle Hospital, PO Box 480, Fremantle, Western Australia 6160.

Accepted for publication 27 Octoher 1988. present in the gut is intimately related to the diet, the now familiar, but so far unproven, association of colon cancer with diet could also be linked in this hypothesis. ${ }^{21}$

Contrastingly, in 1973, Doouss and Castleden ${ }^{24}$ in a study of 1257 autopsies were unable to find a predicted association between the incidences of gall stones and carcinoma of the large bowel. Subsequently, Hoare ${ }^{25}$ and Castleden et $\mathrm{l}^{26}$ reported on the lack of association between cholecystectomy and carcinoma of the colon in retrospective case-control studies. More recently, further reports have appeared questioning the postulated relationship between cholelithiasis and/or cholecystectomy and the subsequent development of colorectal cancer. ${ }^{27-36}$ Most of these have been retrospective case control studies. We have now attempted to examine the question in another way, by comparing the biliary bile acids distribution in patients with colon cancer or gall stones and a control group.

\section{Methods}

SUBJECTS

Patients in the study groups were undergoing 
cholecystectomy for gall stones $(n=13)$, or colonic resection for colon cancer $(n=10)$. Patients in the control group were undergoing highly selective vagotomy or repair of hiatus hernia $(n=8)$. Of the 13 patients undergoing cholecystectomy, four had functioning gall bladders on oral cholecystography. None of the colon cancer or control patients had gall stones or previous cholecystectomy. Their gall bladders appeared normal at operation and did not contain stones on palpation. They were all therefore presumed to have normal functioning gall bladders, although not all had oral cholecystograms. Informed consent was obtained from all patients, and prior approval of the relevant hospital Ethics in Human Experimentation Committees were obtained.

BILE ACIDS ANALYSIS

Bile was obtained by fine needle aspiration from the gall bladder at operation and processed fresh. The bile specimen $(0 \cdot 1$ to $0.2 \mathrm{ml})$ was deproteinised by drop wise addition to a centrifuge tube containing $0 \cdot 1$ $\mathrm{ml}\left[{ }^{1+} \mathrm{C}\right]$-deoxycholate $(2 \mu \mathrm{Ci} / \mathrm{ml})$ and $5 \mathrm{ml}$ methanol. Protein was precipitated by heating for five minutes at $37^{\circ} \mathrm{C}$ with shaking, then centrifuged at $2000 \times g$ for five minutes and washed twice with $2 \mathrm{ml}$ methanol. The combined supernatants were made to $70 \%$ with water and neutral steroids were removed by three $5 \mathrm{ml}$ petroleum ether extractions. The remaining water methanol mixture containing bile acids conjugates, was evaporated to dryness at $40^{\circ} \mathrm{C}$ and the residue dissolved in $4 \mathrm{ml} 1.25 \mathrm{M}$ aqueous $\mathrm{KOH}$ and saponified at 15 psi for three hours. After acidifying with $5 \mathrm{ml} 20 \% \mathrm{NaCl}$ and $5 \mathrm{ml}$ concentrated $\mathrm{HCl}$, bile acids were extracted in diethyl ether $(4 \times 5 \mathrm{ml}$ volumes), and adjusted to $25 \mathrm{ml}$ volume. Thereafter, the ether was evaporated, the residue redissolved in methanol, and the bile acids converted to their methyl esters with ethereal diazomethane as described by Klaassen. ${ }^{37}$ These were further purified by preparative TLC. ${ }^{3 k}$ The region containing the bile acids methyl esters was aspirated from the plate and eluted with $20 \mathrm{ml}$ ethyl acetate. This extract was evaporated to dryness, redissolved in $5 \mathrm{ml}$ methanol and aliquots taken for scintillation counting to calculate recoveries in the extraction procedure.

Dehydrochlate methyl ester ( $100 \mathrm{ug}$ ) was added as an internal standard to duplicate $1 \mathrm{ml}$ aliquots of the methanol solution which were then evaporated to dryness and redissolved in chloroform $(0.5 \mathrm{ml})$ for conversion of the bile acid methyl esters to their trifluoroacetyl derivatives ${ }^{37}$ before gas chromatography.

Dual channel FID analysis was carried out on a Varian 3700 gas-liquid chromatograph equipped with a Hewlett-Packard 3380A recording integrator. Columns were $1.82 \mathrm{~m}$ by $2.5 \mathrm{~mm}$ glass containing $3 \%$
SP-2401 on 100/120 Superlcoport. Column temperature was held at $240^{\circ} \mathrm{C}$ for one minute after injection and then programmed at $1{ }^{\circ} \mathrm{C} /$ minute to $256^{\circ} \mathrm{C}$ where it was maintained for three minutes. Injector and detector temperatures were $305^{\circ} \mathrm{C}$ and carrier gas was $\mathrm{N}_{2}$ at a flow rate of $30 \mathrm{ml} / \mathrm{min}$.

A mixture of bile acid standards was processed with each batch of samples. In order to quantify the patients' bile acid concentrations, an internal standard, 7-ketolithocholic acid, was added to every specimen and standards mixture, and a set of standards was processed simultaneously through the extraction procedure. Another set of standards was derivatised at the end of the procedure. By reference to the area ratio of the internal standard peak, the recoveries of the individual extracted standard bile acids was calculated, and these recovery factors were then applied to the calculation for the recovery of the individual sample bile acids. Reproducibility of the area measurements between replicate samples was such that we were able to quantify amounts of bile acid which represented as little as $1 \%$ of the total standards mixture.

\section{Results}

In all, 13 patients with gall stones, 10 patients with cancer of the colon and eight control patients were studied. The biliary bile acid distributions obtained from these groups of patients are shown in Tables 1 , 2 , and 3 respectively. As will be seen, there was considerable variation in the concentration of total bile acids in $\mathrm{mg} / \mathrm{ml}$ of gall bladder bile in all patients and in all groups of patients. There was no statistically significant variation between any two groups.

The percentage concentration of the individual bile acids in the gall bladder bile are shown in Tables 1,2 , and 3 as well as the proportions of primary and secondary bile acids. When all 31 patients are considered, the mean percentage of secondary bile acids was $27.7 \%$ of the total concentration of bile acids in the gall bladder bile. The median value was $27 \%$. The dotted lines in the column listing the percentages of secondary bile acids in Tables 1, 2, and 3 , separates those patients in each group situated on, above or below the median value.

Because the ratios of primary to secondary bile acids were not normally distributed, non-parametric statistical methodology (the Wilcoxon's rank-sum test), was used to compare the patients in each of the study groups. The patients with gall stones had significantly higher concentrations of secondary bile acids in their biliary bile than the patients in the other two groups $(p<0 \cdot 05)$. There was no significant difference between control and colon cancer groups. These values are shown in Table 4. 
Table 1 Gall stone patients $(n=13)$

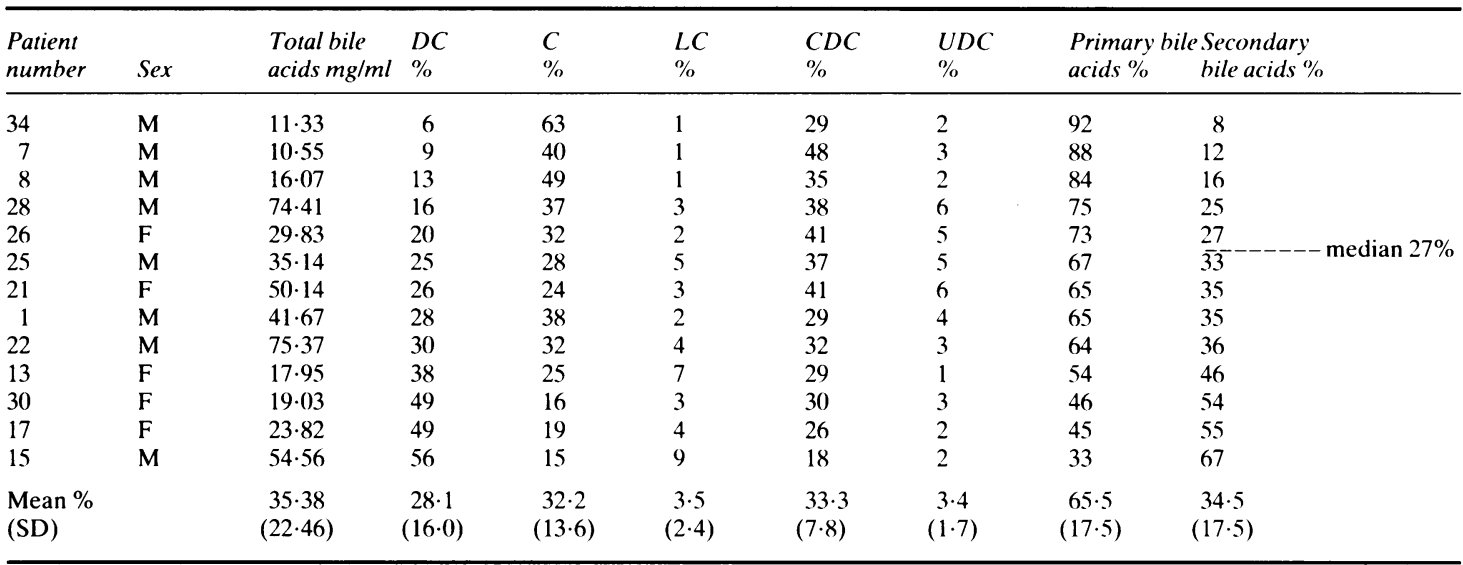

DC - deoxycholic acid; C - cholic acid; LC - lithocholic acid; CDC - chenodeoxycholic acid; UDC - ursodeoxycholic acid.

\section{Discussion}

In this study we have shown that patients with colon cancer have normal concentrations of deoxycholate in their biliary bile, whilst patients with gall stones (before cholecystectomy) have significantly higher biliary deoxycholate concentrations. This is in accord with work by van der Linden et al $l^{29}$ who studied 18 patients with functioning gall bladders both before, and two to three months after, cholecystectomy. They did not find any change in the concentration of secondary bile acids in these patients but confirmed, as we have done, that patients with gall stones tend to have higher concentrations of secondary bile acids in their bile even before cholecystectomy.

Moorehead et $a l^{34}$ recently reported increased chenodeoxycholic acid and reciprocally reduced cholic acid in the duodenal bile of 14 carcinoma patients compared with age and sex matched controls. This compliments the findings of Owen et al $l^{\text {t1 }}$ that the ratio of faecal lithocholic acid to deoxycholic acid is increased in carcinoma patients and in groups with a relatively high risk of developing colon carcinoma.

In the present study there were wide variations between individuals in each group in both total and individual bile acid concentrations in biliary bile, but in contrast with the findings of Moorehead et al, ${ }^{34}$ there were no differences in the mean percentages of individual bile acids when colon cancer patients were compared with controls. This same observation was made by Breuer et $a l^{41}$ in respect of the total and individual bile acid concentrations in the faeces of both control and colon cancer patients. Breuer et al $l^{41}$

Table 2 Colon cancer patients $(n=10)$

\begin{tabular}{|c|c|c|c|c|c|c|c|c|c|c|}
\hline $\begin{array}{l}\text { Patient } \\
\text { number }\end{array}$ & Sex & $\begin{array}{l}\text { Total bile } \\
\text { acids } \mathrm{mg} / \mathrm{ml}\end{array}$ & $\begin{array}{l}D C \\
\%\end{array}$ & $\begin{array}{l}C \\
\%\end{array}$ & $\begin{array}{l}L C \\
\%\end{array}$ & $\begin{array}{l}C D C \\
\%\end{array}$ & $\begin{array}{l}U D C \\
\%\end{array}$ & $\begin{array}{l}\text { Primary bile } \\
\text { acids } \%\end{array}$ & $\begin{array}{l}\text { Secondary } \\
\text { bileacids } \%\end{array}$ & \\
\hline 14 & $\mathbf{M}$ & $9 \cdot 64$ & 2 & 38 & 3 & 55 & 2 & 93 & 7 & \multirow{9}{*}{ median $27 \%$} \\
\hline 12 & $\mathrm{~F}$ & $50 \cdot 85$ & 4 & 38 & 2 & 48 & 8 & 92 & 8 & \\
\hline 5 & $\mathrm{~F}$ & $99 \cdot 28$ & 8 & 55 & 1 & 37 & - & 86 & 14 & \\
\hline 18 & $\mathrm{~F}$ & $84 \cdot 02$ & 14 & 31 & 3 & 42 & 10 & 78 & 22 & \\
\hline 10 & $\mathbf{M}$ & $46 \cdot 44$ & 17 & 38 & 2 & 40 & 3 & 73 & 27 & \\
\hline 2 & $\mathbf{M}$ & $68 \cdot 50$ & 21 & 37 & 4 & 36 & 3 & 73 & 27 & \\
\hline 16 & $\mathbf{M}$ & $66 \cdot 79$ & 23 & 23 & 7 & 42 & 5 & 66 & $3 \overline{4}$ & \\
\hline 9 & $\mathbf{M}$ & $8 \cdot 27$ & 31 & 32 & 1 & 34 & 2 & 6.5 & 35 & \\
\hline 4 & $\mathbf{M}$ & $12 \cdot 95$ & 37 & 19 & 6 & 37 & Trace & 56 & 44 & \\
\hline $\begin{array}{l}\text { Mean \% } \\
\text { (SD) }\end{array}$ & & $\begin{array}{c}51 \cdot 80 \\
(32 \cdot 30)\end{array}$ & $\begin{array}{c}17 \cdot 5 \\
(11 \cdot 2)\end{array}$ & $\begin{array}{r}34 \cdot 9 \\
(9 \cdot 8)\end{array}$ & $\begin{array}{c}3 \cdot 1 \\
(2 \cdot 0)\end{array}$ & $\begin{array}{r}40 \cdot 6 \\
(6 \cdot 6)\end{array}$ & $\begin{array}{c}4 \cdot 0 \\
(3 \cdot 4)\end{array}$ & $\begin{array}{c}75 \cdot 5 \\
(12 \cdot 0)\end{array}$ & $\begin{array}{r}24 \cdot 5 \\
(12 \cdot 0)\end{array}$ & \\
\hline
\end{tabular}

DC - deoxycholic acid: C - cholic acid; LC - lithocholic acid: CDC - chenodeoxycholic acid; UDC - ursodeoxycholic acid. 
Table 3 Control patients $(n=8)$

\begin{tabular}{|c|c|c|c|c|c|c|c|c|c|}
\hline $\begin{array}{l}\text { Patient } \\
\text { number }\end{array}$ & Sex & $\begin{array}{l}\text { Total bile } \\
\text { acids } \mathrm{mg} / \mathrm{ml}\end{array}$ & $\begin{array}{l}D C \\
\%\end{array}$ & $\begin{array}{l}C \\
\%\end{array}$ & $\begin{array}{l}L C \\
\%\end{array}$ & $\begin{array}{l}C D C \\
\%\end{array}$ & $\begin{array}{l}U D C \\
\%\end{array}$ & \multicolumn{2}{|c|}{$\begin{array}{l}\text { Primary bile Secondary } \\
\text { acids } \% \quad \text { bile acids } \%\end{array}$} \\
\hline 33 & $\mathrm{M}$ & $16 \cdot 28$ & 2 & 25 & 4 & 64 & 6 & 90 & 10 \\
\hline 24 & M & $60 \cdot 03$ & 4 & 49 & 2 & 41 & 4 & 88 & 12 \\
\hline 3 & M & $10 \cdot 53$ & 4 & 31 & 12 & 49 & 4 & 87 & 13 \\
\hline 31 & $M$ & 106.45 & 6 & 40 & 2 & 47 & 4 & 87 & 13 \\
\hline 19 & M & $10 \cdot 96$ & 7 & 34 & 1 & 53 & 5 & 80 & 20 \\
\hline 32 & $\mathbf{M}$ & $12 \cdot 05$ & 23 & 32 & 3 & 39 & 2 & 71 & nedian $21 \%$ \\
\hline 29 & $\mathrm{~F}$ & 80.77 & 43 & 23 & 3 & 28 & 4 & 50 & 50 \\
\hline $\begin{array}{l}\text { Mean } \\
(\mathrm{SD})\end{array}$ & & $\begin{array}{c}38 \cdot 78 \\
(38 \cdot 25)\end{array}$ & $\begin{array}{c}13 \cdot 1 \\
(14 \cdot 0)\end{array}$ & $\begin{array}{l}31 \cdot 5 \\
(9 \cdot 9)\end{array}$ & $\begin{array}{c}3 \cdot 9 \\
(3 \cdot 4)\end{array}$ & $\begin{array}{c}47 \cdot 4 \\
(11 \cdot 4)\end{array}$ & $\begin{array}{c}4 \cdot 3 \\
(1 \cdot 2)\end{array}$ & $\begin{array}{c}78 \cdot 6 \\
(13 \cdot 3)\end{array}$ & $\begin{array}{c}21 \cdot 4 \\
(13 \cdot 3)\end{array}$ \\
\hline
\end{tabular}

DC - deoxycholic acid: C - cholic acid; LC - lithocholic acid: CDC - chenodeoxycholic acid; UDC - ursodeoxycholic acid.

concluded that such results did not refute the hypothesis that bile acids are implicated in the pathogenesis of colorectal cancer but they did not support it. In our view, the wide variations in bile acids traversing the gastrointestinal tract in colon cancer and 'normal' patients, and the lack of significant differences between the distribution of primary and secondary bile acids in these two groups, compliment Breuer et al' ${ }^{41}$ findings. We therefore conclude that enterohepatically circulating bile acids are unlikely to play a significant role in the pathogenesis of colon cancer. Given this situation, conditions in which there is a disturbed balance of bile acids distribution in the enterohepatic circulation, such as cholelithiasis or cholecystectomy, are also unlikely to have a significant effect on the incidence of colon cancer via that mechanism, and therefore should not predispose to colon cancer.

The inevitable question therefore, is, why have so many authors found a positive association between gall stones and/or cholecystectomy and carcinoma of the large bowel? Careful study of their papers reveals that many of these authors have only found a significant positive association in women, or in patients who subsequently developed carcinomas in the right colon.

The association may result from a simple juxtaposition of two relatively common conditions in affluent communities. Our group, and others, have shown a much higher incidence of gall stones in women than

Table 4 Ratio of primary and secondary bile acids

\begin{tabular}{lll}
\hline Patients & Primary $\%$ & Secondary \% \\
\hline Controls $(\mathrm{n}=8)$ & $78 \cdot 6$ & $21 \cdot 4$ \\
Colon cancer $(\mathrm{n}=10)$ & $75 \cdot 5$ & $24 \cdot 5$ \\
Gall stones $(\mathrm{n}=13)$ & $65 \cdot 5$ & $34 \cdot 5 *$ \\
\hline
\end{tabular}

${ }^{*} \mathrm{p} \leqslant 0 \cdot 05$ (Wilcoxon test). men beyond the age of 50. ${ }^{24+2}$ Furthermore, it is becoming apparent that, in these communities, right sided colonic cancers are more common in women, whilst cancers of the left colon and rectum are more common in men. ${ }^{43}$ Thus, a random selection of women is more likely to have gallstones than men; similarly a random sample of women is more likely to have right sided colon cancers than men. Because both conditions are relatively common in Western societies, any study which fails to take account of this sex difference will inevitably find an association between cholecystectomy and cancer of the right colon in women.

Unfortunately, the arguments which attempt to link this association causally to enterohepatically circulating bile acids are not supported by consistent findings in analytical studies such as ours, or indeed by consistency in retrospective case control studies, or autopsy studies. Indeed Hill ${ }^{44}$ has more recently concluded that bile acids are not initiators of large bowel carcinogenesis but may be involved as promoters of the adenoma carcinoma sequence. If this were the case, then the multiplicity of factors, such as genetic susceptibility, environmental modulation and very long latency, which are known to influence the adenoma carcinoma sequence ${ }^{45}$ would explain why there is no consistency in the results of studies which attempt to link bile acids, cholelithiasis or cholecystectomy to the clinical incidence of colorectal cancer in man.

\section{References}

1 Vernick LJ, Kuller LH, Lohsoonthorn P, Rycheck RR, Redmond CK. Relationship between cholecystectomy and ascending colon cancer. Cancer $1980 ; 45$ : 392-5.

2 Linos DA, Beard CM, O'Fallon WM, Dockerty MB, Beart RW, Kurland LT. Cholecystectomy and carcinoma of the colon. Lancet 1981; ii: 379-81.

3 Turnbull PRG, Smith AH, Isbister WH. Cholecystec- 
tomy and cancer of the large bowel. Br J Surg 1981; 68: 551-3.

4 Turunen MJ, Kivilaakso EO. Increased risk of colorectal cancer after cholecystectomy. Ann Surg 1981; 194: 639-41.

5 Manousos ON, Gerovassilis F, Papadimitriou C, Tzonou A, Polychronopoulou A, Trichopoulos D. Cholecystectomy and colon cancer. Lancer 1981; ii: 810.

6 Vernick LJ, Kuller LH. A case-control study of cholecystectomy and right-side colon cancer: the influence of alternative data sources and differential interview participation proportions on odds ratio estimates. Am J Epidemiol 1982; 116: 86-101.

7 Lowenfels AB, Domellof L, Lindstrom CG, Bergman F, Monk MA, Sternby NH. Cholelithiasis, cholecystectomy and cancer: a case control study in Sweden. Gastroenterology 1982; 83: 672-6.

8 Linos DA, O'Fallon WM, Thistle JL. Kurland LT. Cholelithiasis and carcinoma of the colon. Cancer 1982; 50: 1015-9.

9 Markman M. Cholecystectomy and carcinoma of the colon. Lancet 1982; ii: 47.

10 Weiss NS, Daling JR, Chow WH. Cholecystectomy and the incidence of cancer of the large bowel. Cancer 1982; 49: 1713-5.

11 Alley PG, Lee SP. The increased risk of proximal colonic cancer after cholecystectomy. Dis Colon Rectum 1983; 26: 522-4.

12 Kwai AH. Cholecystectomy and large bowel cancer. Mt Sinai J Med NY 1983; 50: 359-63.

13 Narisawa T, Sano M, Sato M, Takahashi T, Arakawa H. Relationship between cholecystectomy and colonic cancer in low-risk Japanese population. A preliminary study. Dis Colon Rectum 1983; 26: 512-5.

14 Hill MJ. Bilc, bacteria and bowel cancer. Gut 1983; 24: $871-5$.

15 Gafa M, Sarli L, Sgobba G, Sensebastiano G, Lupi M, Peracchia A. Cholelithiasis and colorectal cancer. Ital J Surg Sci 1984; 14: 43-7.

16 Allende HD, One FV, Davis HT. Gallbladder discase: risk factor for colorectal carcinoma? J Clin Gastroenterol 1984; 6: 51-5.

17 Aries VC, Crowther JS, Drasar BS, Hill MJ, Williams REO. Bacteria and the aetiology of cancer of the large bowel. Gut 1969; 10: 334-5.

18 Hill MJ, Crowther JS, Drasar BS, Hawksworth G, Aries $\mathrm{V}$, Williams REO. Bacteria and the aetiology of cancer of the large bowel. Lancet 1971; i: 95-100.

19 Hill MJ, Drasar BS. Bacteria and the aetiology of cancer of the large bowel. In: Balows A. DeHaan RM, Dowell VR, Guze LB, cds. Anaerobic bacteria: role in disease. Springfield, Illinois: Charles C Thomas, 1974: 119-39.

20 Hill MJ. Bacteria and the etiology of colonic cancer. Cancer 1974; 34: 81.5-8.

21 Hill MJ. Metabolic epidemiology of dietary factors in large bowel cancer. Cancer Res 1975; 35: 3398-402.

22 Pomare EW. Heaton KW. The effect of cholecystectomy on bile salt metabolism. Gut 1973; 14: 753-62.

23 Malagelada JR, Go VLW, Summerskill WHJ, Gamble WS. Bile acid secretion and biliary bile acid composition altered by cholecystectomy. Am J Dig Dis 1973; 18: $455-9$.
24 Doouss TW, Castleden WM. Gallstones and carcinoma of the large bowel. NZ Med J 1973; 77: 162-5.

25 Hoare AM. Carcinoma of the colon and cholecystectomy. Lancet 1974; ii: 1395-6.

26 Castleden WM. Doouss TW. Jennings KP. Leighton M. Gallstones, carcinoma of the colon and diverticular disease. Clin Oncol 1978; 4: 139-44.

27 Simi M, Leardi S, Siciliano R, Scappaticci G, Costantini FM, Speranza V. Cancer of the large intestine and previous cholecystectomy: does a relationship really exist? Ital J Surg Sci 1985: 15: 175-80.

28 Moorehead RJ, Kernohan RM, Patterson CC. McKelvey STD, Parks TG. Does cholecystectomy predispose to colorectal cancer? A case control study. Dis Colon Rectum 1986; 29: 36-8.

29 Van der Linden W, Katzenstein B, Nakayama F. The possible carcinogenic effect of cholecystectomy. No post-operative increase in the proportion of secondary bile acids. Cancer 1983; 52: 1265-8.

30) Abrams JS, Anton JR, Dreyfuss DC. The absence of a relationship between cholecystectomy and the subsequent occurrence of cancer of the proximal colon. Dis Colon Rectum 1983; 26: 141-4.

31 Adami HO, Meirik O, Gustavsson S, Nyren O, Krusemo UB. Colorectal cancer after cholecystectomy: absence of risk increase within 11-14 years. Gastroenterology 1983; 85: 859-65.

32 Blanco D, Ross RK. Paganini-Hill A. Henderson BE. Cholecystectomy and colonic cancer. Dis Colon Rectum 1984; 27: 290-2.

33 Fixa B, Komarkova O, Zaydlar K, Bures J, Erben J. Is there an increased risk of colorectal cancer after cholecystectomy? Neoplasma 1985; 32: 513-7.

34 Spitz MR, Russell NC, Guinee VF, Newell GR. Questionable relationship between cholecystectomy and colon cancer. J Surg Oncol 1985; 30: 6-9.

35 Ichimiya $\mathrm{H}$, Kono S, Ikeda M. Tokudome S, Nakayama F, Kuratsune $M$. Cancer mortality among patients undergoing cholecystectomy for benign biliary diseases. Jpn J Cancer Res 1986; 77: 579-83.

36 Kaibara N, Wakatsuki T, Mizusawa K. Sugesawa A, Kimura O, Koga S. Negative correlation between cholecystectomy and the subsequent development of large bowel carcinoma in a low-risk Japanese population. Dis Colon Rectum 1986; 29: 644-6.

37 Klaassen CD. Gas-liquid chromatographic determination of bile acids in bile. Clin Chim Acta 1971; 35: 225-9.

38 Grundy SM, Ahrens EH. Miettinen TA. Quantitative isolation and gas-liquid chromatographic analysis of total faecal bile acids. J Lipid Res 1965; 6: 397-410.

39 Moorehead RJ, Campbell GR, Donaldson JD, McKelvey STD. Relationship between duodenal bile acids and colorectal neoplasia. Gut 1987; 28: 1454-9.

40) Owen RW, Henly PJ, Day D, Thompson MH, Hill MJ. Faccal steroids and colorectal cancer: bile acid profiles in low and high risk groups. Br J Surg 1985; 72 [suppl]: 137.

41 Breuer NF, Dommes P, Jackel S, Goebell H. Fecal bile acid excretion pattern in colonic cancer patients. Dig Dis Sci 1985; 30: 852-9. 
42 Bateson MC, Bouchier IAD. Prevalence of gall stones in Dundee: a necropsy study. $\mathrm{Br}$ Med J 1975; iv: 427-30.

43 Stewart RJ, Stewart AW, Turnbull PRG, Isbister WM. Sex differences in subsite incidence of large-bowel cancer. Dis Colon Rectum 1983; 26: 658-60.
44 Hill MJ. Cancer of the large bowel: human carcinogenesis. Br J Surg 1985; 72 [suppl]: 37.

45 Morson BC, Bussey HJR, Day DW, Hill MJ. Adenomas of the large bowel. Cancer Surv 1983; 2: 45177. 